\title{
Changes in the photosynthetic efficiency of winter wheat in response to abiotic stress
}

Research Article

Krisztina Balla*, Szilvia Bencze ${ }^{1}$, Péter Bónis², Tamás Árendás², Ottó Veisz

${ }^{1}$ Cereal Resistance Breeding Department,

${ }^{2}$ Crop Production Department, Agricultural Institute,

Centre for Agricultural Research, Hungarian Academy of Sciences,

H-2462 Martonvásár, Hungary

Received 18 June 2013; Accepted 19 September 2013

Abstract: The assessment of heat and drought tolerance is of primary importance in breeding programmes designed to improve heat and drought tolerance in cereals. Three winter wheat varieties grown in controlled growth chambers were exposed to heat $(H)$ and drought (D) stress singly and in combination $(\mathrm{H}+\mathrm{D})$. The combined effects of $\mathrm{H}$ and $\mathrm{D}$ stress were much more severe than those of individual treatments for both physiological and yield parameters during grain filling. The chlorophyll content, effective quantum yield of PSII, net assimilation rate, transpiration, stomatal conductance and intercellular $\mathrm{CO}_{2}$ concentration were greatly reduced by $\mathrm{H}, \mathrm{D}$ and their interaction. Grain yield decreased to a greater extent (48.3\%) in Plainsman V, averaged over the stress treatments, than in Mv Magma $(67.8 \%)$ and Fatima 2 (53.7\%). The least decline was found in grain number, except in Plainsman V. Mv Magma tolerated heat stress better than Fatima 2. In terms of photosynthetic activity, Plainsman V showed better drought tolerance than Mv Magma. The results showed that changes in physiological properties during stress treatment are not always associated with changes in yield parameters, so a combination of methods may be needed to give a more precise picture of the stress tolerance of wheat varieties.

Keywords: Heat stress $\bullet$ Drought $\bullet$ Photosynthesis $\bullet$ Grain yield $\bullet$ Grain filling $\bullet$ Winter wheat

(c) Versita Sp. z 0.0 .

\section{Abbreviations:}

$\mathrm{Ci} \quad$ - intercellular $\mathrm{CO}_{2}$ concentration;

$\mathrm{D}$ - drought stress;

$\mathrm{D}+\mathrm{H}$ - drought + heat stress;

E - transpiration;

Fat - Fatima 2;

$g_{\mathrm{s}} \quad$ - stomatal conductance;

$\mathrm{H}$ - heat stress;

Mag - Mv Magma;

PAM - pulse amplitude modulated fluorometer;

$\mathrm{Pla}$ - Plainsman V.;

$P_{N} \quad$ - net assimilation rate;

$\Phi_{\mathrm{PSII}}$ - effective quantum yield of PSII

\section{Introduction}

Temperature and drought have an extremely complex effect on the intensity of photosynthesis, as they influence numerous physiological processes, which in turn exert an effect on photosynthetic activity [1]. The optimum functioning of photosynthetic processes may depend on a number of other factors, including light intensity, $\mathrm{CO}_{2}$ concentration, the plant's water balance, and whether the plants investigated are of the $\mathrm{C} 3$ or C4 type. Many factors may lead to a deterioration in photosynthetic intensity if they are not satisfactory for the plant.

Various studies show that photosynthesis in wheat leaves starts to decline at temperatures between 28 and $35^{\circ} \mathrm{C}[2,3]$. Heat stress during the reproductive phase may cause pollen sterility, tissue dehydration and lower $\mathrm{CO}_{2}$ assimilation [1]. High temperatures injure the processes responsible for light gathering and light energy conversion, while increasing the level of photorespiration. The light-harvesting chlorophyllprotein complex may be irreversibly severed from the reaction centre nucleus, and the water-splitting system responsible for oxygen generation may also be 
damaged [4]. All these processes have a negative effect on photosynthesis and respiration $[5,6]$. The inhibition of photosystem II (PSII) electron transport in response to heat stress is often indicated by a sharp increase in the basal level of chlorophyll fluorescence [7]. Heat stress was found by these authors to cause damage to the thylakoids, as indicated by the increase in the ratio of constant fluorescence and the peak of variable fluorescence. Other results suggested that heat-induced damage to the thylakoids was closely associated with chlorophyll loss in winter wheat $[8,9]$.

The temperature dependence of stomatal closure and opening is of key importance, as this influences the flow of $\mathrm{CO}_{2}$ from the atmosphere into the leaves. High temperature causes an increase in transpiration, which induces stomatal closure. This has an indirect effect on the photosynthetic carbon dioxide fixation of the plants. In addition, the activity of the enzymes involved in $\mathrm{CO}_{2}$ assimilation also exhibits temperature dependence, which may have a damaging effect on the activity of Rubisco carboxylase and oxygenase [10]. These authors found that a heat stress $\left(34 / 17^{\circ} \mathrm{C}\right)$ for 12 days rapidly reduced the Rubisco activity, whereas that of PEP carboxylase increased initially, but later declined in all organs.

The kinetic properties of Rubisco suggest that photosynthesis may be directly inhibited if the temperature rises to over $30^{\circ} \mathrm{C}$. In the case of moderate heat stress, over a temperature range of $30-42^{\circ} \mathrm{C}$, this inhibition appears to be due to the slower regeneration of ribulose-1,5-bisphosphate (RuBP), which can be attributed to the disruption of electron transport and the inactivation of enzymes responsible for the evolution of oxygen in PSII [11].

High temperature is often accompanied by drought. In response to drought there is a substantial drop in the rate of photosynthesis, resulting in a great reduction in the net $\mathrm{C}$ (carbon molecule) incorporation into the plants [12]. One reason for the decline in photosynthetic activity is stomatal closure, which may be due to a drop in leaf turgor or to low atmospheric moisture content, but the water content of the soil plays a greater role in causing stomatal closure than the water status in the leaves.

The inhibition of photosynthesis is usually preceded by stomatal closure, which means that less $\mathrm{CO}_{2}$ is available at assimilation sites in the chloroplasts. However, photosynthesis can also be limited in a nonstomatal manner due to a reduction in the efficiency of carboxylation [13], RuBP regeneration or the inhibition of chloroplast activity [14].

Drought during grain filling was found to accelerate plant senescence in wheat and to enhance the remobilisation of carbohydrates stored prior to anthesis from the straw and leaves into the grains [15]. The first sign of plant senescence is the breakdown of chlorophyll molecules, which leads to the retardation of photosynthetic activity $[16,17]$. Because photosynthesis is one of the main metabolic processes influencing yield properties in cereals [7], chlorophyll fluorescence, net photosynthetic activity and chlorophyll content are frequently used to monitor the ability of wheat to adapt to abiotic stress factors such as drought and heat. As chlorophyll fluorescence exhibits a correlation with heat tolerance, it could be a promising trait for selection [18]. Physiological evidence indicates that the loss of chlorophyll content is closely related to a reduction in yield in the field $[8,19]$.

As extreme weather conditions are becoming increasingly frequent and often affect wheat plants after heading, research on the response to heat and drought stress during the grain-filling period is of primary importance in Hungary. The present work on the stress tolerance of winter wheats thus investigated not only the grain-filling process and the grain yield, but also how photosynthetic efficiency was influenced by high temperature $\left(35 / 20^{\circ} \mathrm{C}\right)$ and water deficiency.

\section{Experimental Procedures}

Three winter wheat varieties with very different genetic backgrounds were chosen for the physiological analysis: Plainsman V (USA), a hard-grained winter wheat with high protein content and good drought tolerance, Mv Magma, a high quality bread wheat with medium early ripening and excellent yield potential, and Fatima 2, a mid-early maturing cultivar known for its excellent yield potential and for the good milling and baking quality of its flour, which can be used to bake bread of excellent quality.

The studies were carried out in a Conviron PGV36 climate chamber in the Martonvásár phytotron, to investigate the effect of high temperature and drought stress, both individually and in combination, on the photosynthetic processes of winter wheat.

Pots with a volume of $2700 \mathrm{~cm}^{3}$, containing a known quantity of a 3:2:1 ratio of soil, Vegasca and sand, were each planted with four germinated wheat seeds. After 6 weeks of vernalisation at $4^{\circ} \mathrm{C}$, the plants were grown using the T2NY2 spring-summer climate programme [20], watered daily and given a twice-weekly supply of nutrients (Volldünger Solution, Linz, Austria, in tapwater) until the start of the stress treatment.

The experiment consisted of four treatments: control (C), heat stress $(H)$, drought stress $(D)$ and heat + drought stress $(H+D)$. There were a total of 36 pots 
for each variety, 9 per treatment, with 4 plants per pot. Treatment began 12 days after heading (Zadoks-75, [21]) and was continued for 15 days. The temperature was set at $24 / 20^{\circ} \mathrm{C}$ (day/night) in the control chamber [20] and at $35 / 20^{\circ} \mathrm{C}$ in the heat stress treatment. Soil moisture was adjusted to $60-70 \%$ of natural water content (NWC, taken as 100\%) in the control and to $40-45 \%$ in the drought stress treatment. Water was added on a weight basis. The light intensity was adjusted to $350 \mu \mathrm{mol} \mathrm{m} \mathrm{m}^{-2} \mathrm{~s}^{-1}$ during the stress treatments.

The chlorophyll content was measured on the flag leaves using a SPAD-502 instrument (Minolta, Japan), which records leaf transmittance in the red and nearinfrared spectra and then calculates the SPAD index from these two values. Measurements were made on the $3^{\text {rd }}, 7^{\text {th }}, 9^{\text {th }}, 11^{\text {th }}, 13^{\text {th }}$ and $15^{\text {th }}$ days of treatment.

The effective quantum yield of PSII, $\Phi_{\text {PSII }}$, calculated as $\Delta F / F_{m}{ }^{\prime}=\left(F_{m}{ }^{\prime}-F_{s}\right) / F_{m}{ }^{\prime}$ (where $F_{m}{ }^{\prime}$ and $F_{s}$ represent the maximum and steady state fluorescence levels, respectively, in the light-adapted state: [22]), was measured on the flag-leaves at ambient light intensity (300 $\mu \mathrm{mol} \mathrm{m} \mathrm{m}^{-2} \mathrm{~s}^{-1}$ PAR at the height of measurement) in the growth chambers using a pulse amplitude modulated fluorometer (PAM-2000, Walz, Effeltrich, Germany). White light with an intensity of $8000 \mu \mathrm{mol} \mathrm{m} \mathrm{m}^{-2} \mathrm{~s}^{-1}$ was used as saturating light. Measurements were made on the $3^{\text {rd }}, 6^{\text {th }}, 9^{\text {th }}, 11^{\text {th }}$ and $14^{\text {th }}$ days of treatment on the flag-leaves.

Changes in the net assimilation rate $\left(P_{N}\right)$, transpiration $(E)$, stomatal conductance $\left(g_{s}\right)$ and intercellular $\mathrm{CO}_{2}$ concentration $\left(\mathrm{C}_{i}\right)$ of the plants were measured using an LI-6400 Portable Photosynthesis System (LI-COR, Inc., Lincoln, NE, USA) on the $3^{\text {rd }}, 6^{\text {th }}$, $9^{\text {th }}, 11^{\text {th }}$ and $14^{\text {th }}$ days of treatment. The leaves were kept in a leaf chamber during the measurements. External air was scrubbed of $\mathrm{CO}_{2}$ and mixed with a supply of pure $\mathrm{CO}_{2}$ to create a reference concentration of $400 \mu \mathrm{mol} \mathrm{m}^{-2}$ $\mathrm{s}^{-1}$. The quantum flux was set to $350 \mu \mathrm{mol} \mathrm{m} \mathrm{m}^{-2} \mathrm{~s}^{-1}$ and the flow rate to $500 \mu \mathrm{mol} \mathrm{m} \mathrm{m}^{-2} \mathrm{~s}^{-1}$. The temperature inside the leaf chamber was maintained at $35^{\circ} \mathrm{C}$ in treatments $\mathrm{H}$ and $\mathrm{H}+\mathrm{D}$ and at $24^{\circ} \mathrm{C}$ in treatments $\mathrm{C}$ and $\mathrm{D}$.

After harvest maturity was reached, the grain yield per plant, kernel number, thousand-kernel weight (TKW) and harvest index $(\mathrm{HI})$ were determined, the latter as (grain yield/biological yield) $\times 100 \%$, as proposed by Donald (1962) [23].

The data were statistically evaluated using two-way analysis of variance (ANOVA) with replications [24]. Chlorophyll content and $\Phi_{\text {PSII }}$ were determined on twenty samples and the other photosynthetic parameters $\left(P_{N}\right.$, $g_{s}, E, C_{i}$ ) on the leaves of sixteen chosen plants. The grain yield parameters were recorded for twenty-four samples. To aid comparison, the data are given as a \% of the control values. Least significant differences (LSD) denoted by ${ }^{*},{ }^{* *}$ or ${ }^{* * *}$ represent significance at the $P \leq 0.05, P \leq 0.01$ and $P \leq 0.001$ levels, respectively.

\section{Results}

The sensitivity of individual winter wheats to high temperature and drought may differ considerably, especially during grain filling, as plants are particularly sensitive to water deficit and high temperature in the reproductive phases. After flowering, wheat plants exposed to stress factors exhibited accelerated aging, the first sign of which was the gradual degradation of the chlorophyll molecules, leading to the yellowing of the leaves and a reduction in photosynthetic activity (Figure 1). Among the winter wheat varieties tested, Mv Magma and Plainsman $\mathrm{V}$ had better tolerance of high temperature, as the chlorophyll content only decreased slightly up to the $11^{\text {th }}$ day, while Fatima 2 was more sensitive, responding with a significant decline by the $9^{\text {th }}$ day (Figure 1A). Drought stress, however, caused a reduction in the chlorophyll contents of all three varieties by the $9^{\text {th }}$ day of treatment. Plainsman $\checkmark$ proved to be the most resistant, as the SPAD values of Mv Magma and Fatima 2 decreased to a greater extent in response to water withholding (Figure 1B). The combined application of the two stress factors resulted in a more intensive change in the chlorophyll content in all the varieties, though Mv Magma had the best tolerance of combined stress, while Plainsman $\mathrm{V}$ was the most sensitive, responding with a sudden drop in the chlorophyll content on the $9^{\text {th }}$ day (Figure $1 \mathrm{C}$ ).

A higher rate of photosynthesis is indicative of better stress tolerance, but chlorophyll fluorescence could also be a suitable trait for selection. In the present experiment the stress treatments caused substantial differences in the effective quantum yield of PSII $\left(\Phi_{\text {PSII }}\right)$ (Figure 2). As previously shown by changes in the chlorophyll content, in response to heat stress the effective quantum yield of Mv Magma remained at the highest level, while that of Fatima decreased to the greatest extent (Figure 2A).

When drought stress was applied the values remained constant until the $11^{\text {th }}$ day, after which only slight differences could be detected between the $\Phi_{\text {PSII }}$ values of the three varieties (Figure 2B), though the drought tolerance of Plainsman $\mathrm{V}$ proved to be somewhat better than that of Mv Magma and Fatima 2.

The combined heat + drought stress treatment affected the varieties to the greatest extent (Figure $2 \mathrm{C}$ ). The effective quantum yield of Mv Magma was the least sensitive to the combined stress, remaining significantly higher than that of the other two wheat varieties until the 

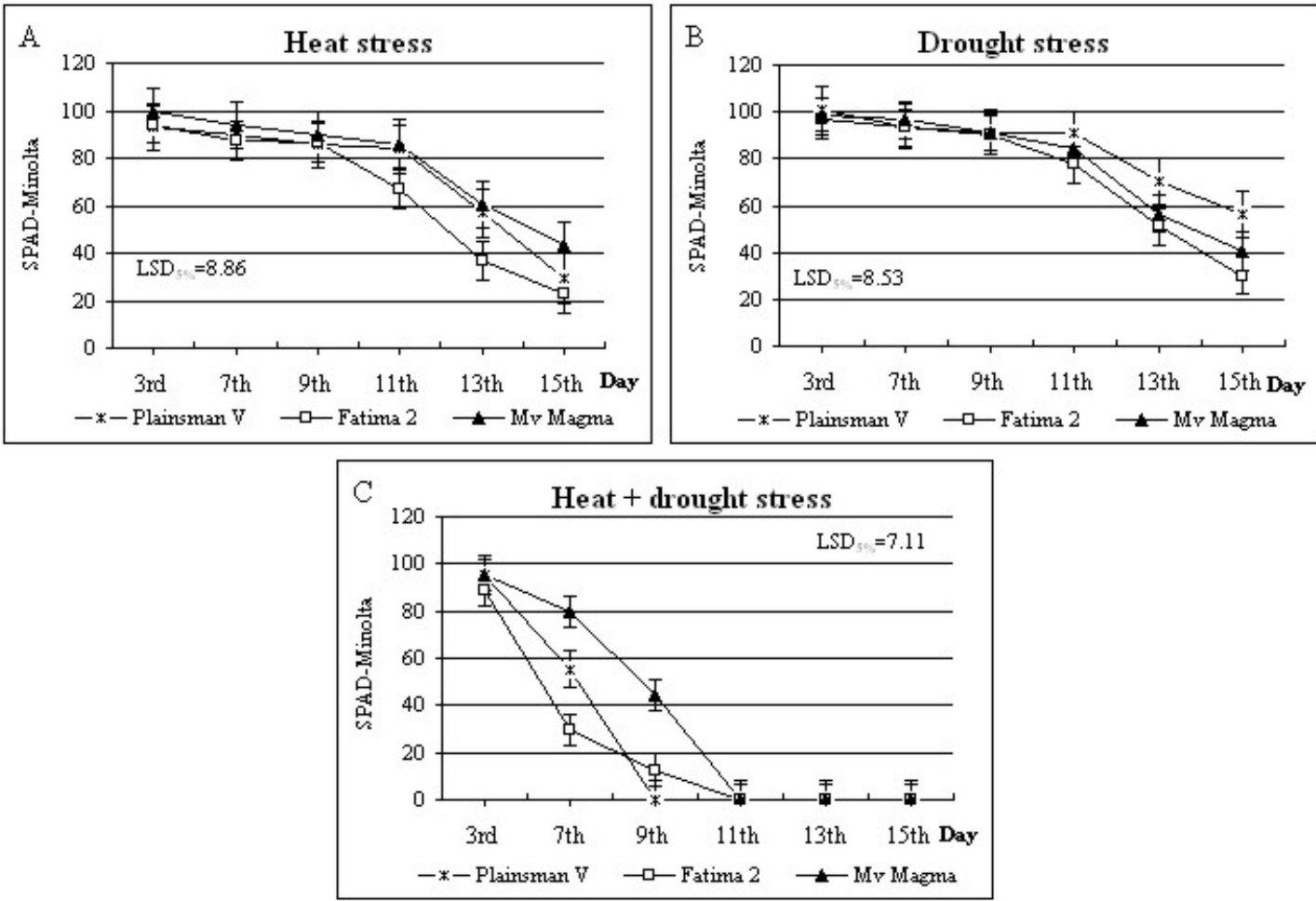

Figure 1. Changes in the chlorophyll content of winter wheats (as a \% of the control) during 15-day treatment with heat stress (A), drought stress (B) and combined heat + drought stress $(C) L_{5 D_{5 \%}}$ : Bar - represents the minimal difference statistically significant at the $P \leq 0.05$ level
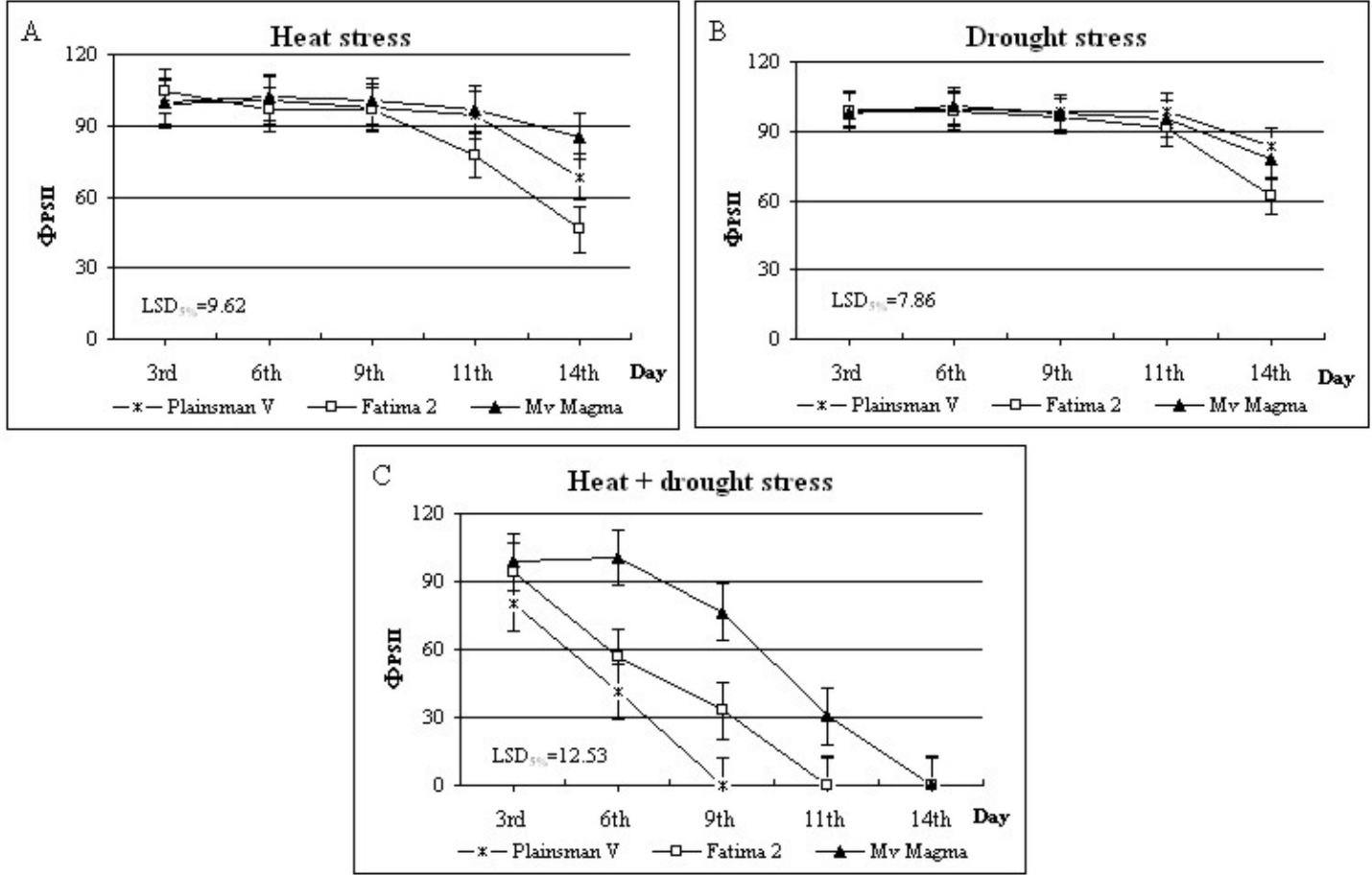

Figure 2. Changes in the effective quantum yield of PSII $\left(\Phi_{\mathrm{PSI}}\right)$ as a \% of the control during 15 days of heat stress $(\mathrm{A})$, drought stress $(\mathrm{B})$ and combined heat + drought stress $(C) L_{5 D_{5}}$ : Bar - represents the minimal difference statistically significant at the $\mathrm{P} \leq 0.05$ level 
$14^{\text {th }}$ day. Fatima 2 also proved to have better tolerance of combined stress than Plainsman $\mathrm{V}$, as revealed by its consistently higher $\Phi_{\text {PSII }}$ values.

When investigating photosynthetic activity, considerable changes were found after stress treatment in the net assimilation $\left(P_{N}\right)$, stomatal conductance $\left(g_{s}\right)$, transpiration $(E)$ and intercellular $\mathrm{CO}_{2}$ concentration $\left(\mathrm{C}_{\mathrm{i}}\right)$ of the plants.

In response to heat stress the net assimilation of Plainsman $\mathrm{V}$ began to decline from the $9^{\text {th }}$ day, while that of Mv Magma proved to be much more stable (Figure $3 A$ ). The smaller reduction in the $P_{N}$ value indicated that this variety was less sensitive to a temperature of $35^{\circ} \mathrm{C}$ than Plainsman $\mathrm{V}$. The least tolerant variety was Fatima 2, where the net photosynthetic assimilation dropped to $30 \%$ of the control value. This value was $47.7 \%$ for Plainsman $\mathrm{V}$, while in the case of Mv Magma the net carbon dioxide assimilation was still $73.7 \%$ of the control value on the $14^{\text {th }}$ day. In the case of drought stress, the highest $P_{N}$ value was recorded between the $9^{\text {th }}$ and $11^{\text {th }}$ days of treatment for Plainsman $\mathrm{V}$, when the net assimilation of Fatima 2 and Mv Magma exhibited a considerable decline (Figure 3B). An analysis of the effect of combined stress revealed a similar extent of damage in Plainsman V and Fatima 2, while Mv Magma tolerated the stress significantly better up to the $11^{\text {th }}$ day of treatment (Figure 3C).

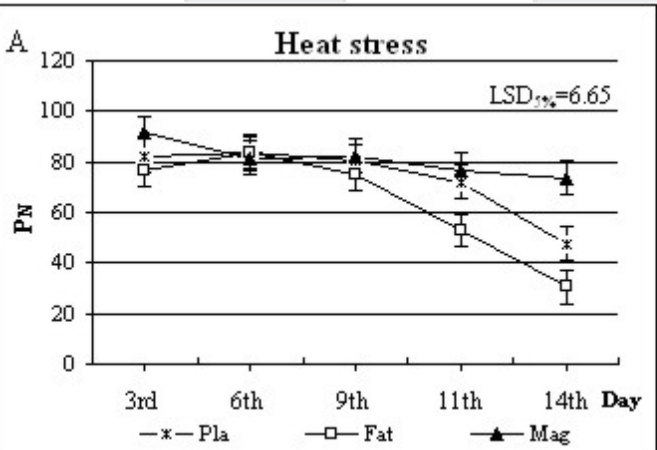

When investigating changes in transpiration $(E)$, the values were found to be far higher than in the control plants at the beginning of heat stress, as the stressed plants attempted to combat the effects of high temperature by increasing their transpiration (Figure 4A). On the third day of treatment the highest value was recorded for $\mathrm{Mv}$ Magma, and although the level of transpiration gradually declined, it was still higher than for the other varieties on the last day of treatment. The greatest reduction was observed for Fatima 2 on the $14^{\text {th }}$ day of treatment.

The plants attempted to survive drought stress by reducing their transpiration. The closing of the stomata results in lower water losses. In response to water withholding, the $E$ values dropped to well below the control values (Figure 4B). No great differences could be observed between the varieties, though the value recorded for Plainsman $\mathrm{V}$ was the highest on the $11^{\text {th }}$ day of treatment ( $46 \%$ of the control), while that of $\mathrm{Mv}$ Magma was lowest.

While drought stress alone resulted in an average $26 \%$ reduction in transpiration by the $14^{\text {th }}$ day of treatment, the combined heat + drought stress caused an even more intense decrease: transpiration ceased completely by the $9^{\text {th }}$ day in varieties Plainsman $\mathrm{V}$ and Fatima 2, and on the $11^{\text {th }}$ day for Mv Magma (Figure 4C).

The values of stomatal conductance $\left(g_{s}\right)$ demonstrate the extent to which the stomata open. The changes

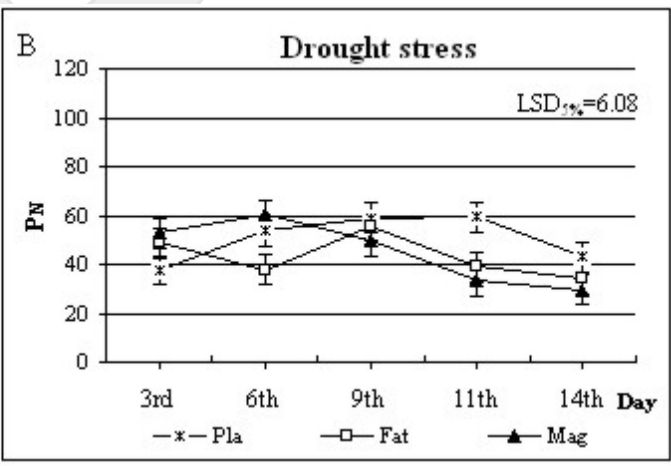

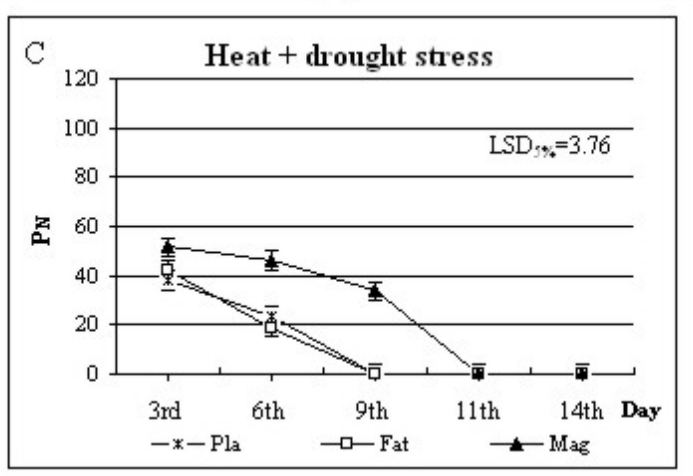

Figure 3. Changes in the net assimilation $\left(P_{N}\right)$ of winter wheats as a \% of the control during 15 days of treatment with heat stress $(A)$, drought stress (B) and combined heat + drought stress (C) Pla - Plainsman V, Fat - Fatima 2, Mag - Mv Magma $L_{S D_{5 \%}}$ : Bar - represents the minimal difference statistically significant at the $\mathrm{P} \leq 0.05$ level 

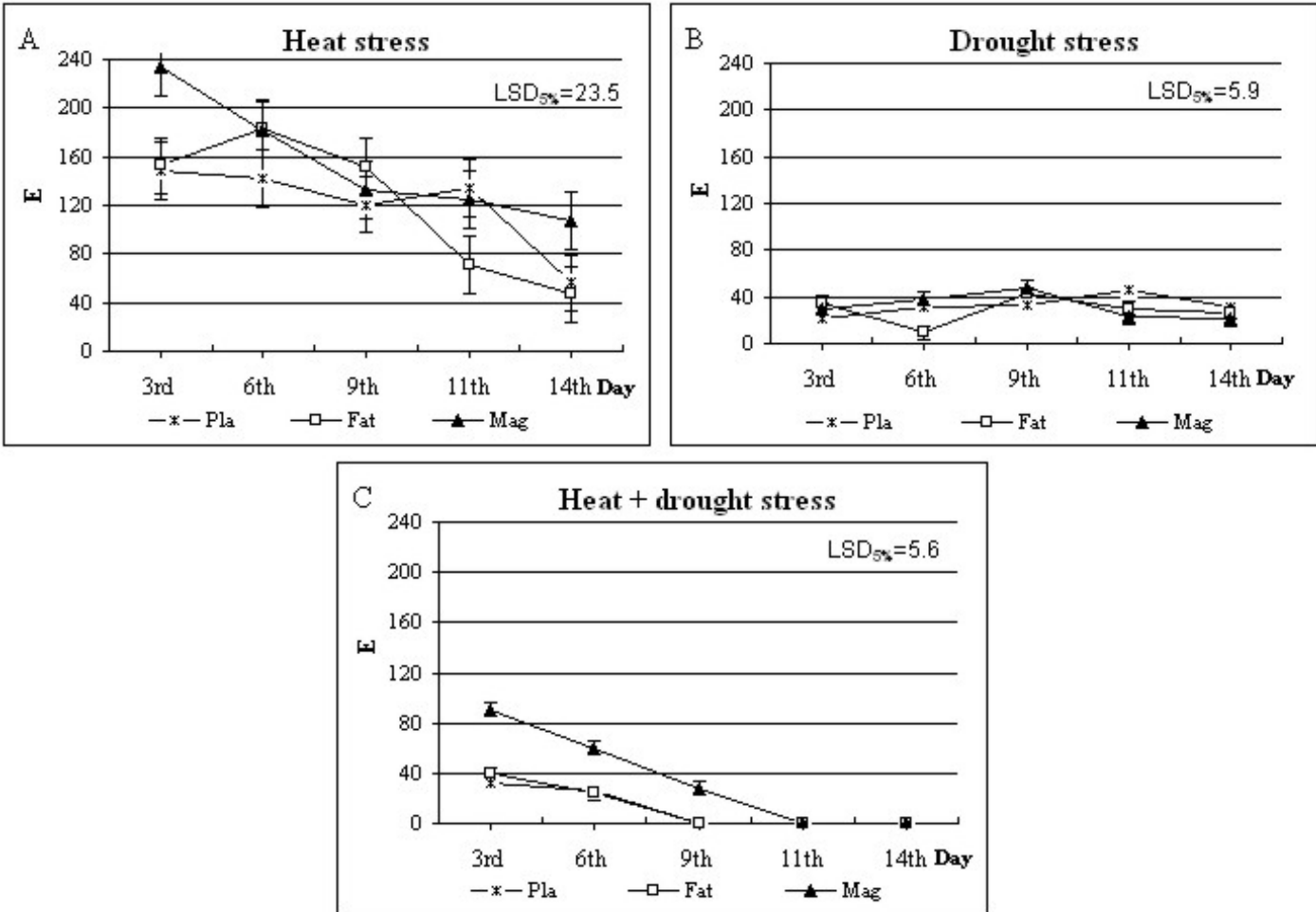

Figure 4. Changes in the transpiration $(E)$ of winter wheats as a \% of the control during 15 days of treatment with heat stress (A), drought stress (B) and combined heat + drought stress (C) Pla - Plainsman V, Fat - Fatima 2, Mag - Mv Magma LSD $5 \%$ : Bar - represents the minimal difference statistically significant at the $\mathrm{P} \leq 0.05$ level

observed in response to heat stress revealed the least decline in stomatal conductance for Mv Magma (to 33\% of the control) and more severe reductions for Fatima 2 and Plainsman $\mathrm{V}(17 \%$ and $13.3 \%$, respectively) compared to the control (Figure 5A).

When drought stress was applied, the stomatal conductance of the varieties dropped to an even greater extent, with the least reduction for Plainsman $\mathrm{V}$ (to $28 \%$ of the control) and the greatest for Mv Magma (to 10\% of the control) by the $14^{\text {th }}$ day of treatment (Figure 5B).

In response to combined stress the changes in $g_{s}$ were similar to those observed for transpiration, with values of $0 \%$ by the $9^{\text {th }}$ day for Plainsman $V$ and Fatima 2 and by the $11^{\text {th }}$ day for Mv Magma (Figure $5 \mathrm{C}$ ). The effect of $H+D$ was so severe that the plants were unable to protect themselves from this combined treatment.

An analysis of changes in the intercellular $\mathrm{CO}_{2}$ concentration $\left(C_{i}\right)$ showed the greatest reduction in response to combined stress, while heat or drought stress alone caused less pronounced changes. The more intensive transpiration induced by treatment at $35^{\circ} \mathrm{C}$ led to a reduction in the intercellular $\mathrm{CO}_{2}$ concentration (Figure 6A), while drought stress resulted in a slight increase due to the closure of the stomata (Figure 6B).
The highest $C_{i}$ value in the heat stress treatment was recorded for Mv Magma (80.8\%), while Plainsman V and Fatima 2 were characterised by values of $63.6 \%$ and $67.7 \%$. In the drought stress treatment, Mv Magma had the highest $C_{i}$ value on the $9^{\text {th }}$ day, but by the end of the treatment period a higher value was detected for Fatima 2. In response to combined stress Plainsman $\mathrm{V}$ and Fatima 2 exhibited a pronounced reduction in the $C_{i}$ value, while the decline was less severe for Mv Magma, as also observed for the other parameters.

In response to the abiotic stress treatments changes were observed in the photosynthetic activity of the plants, resulting in changes in yield traits. The varieties examined responded differently to the various stress factors (Table 1).

In terms of biomass, the combined stress generally had the greatest effect for all the varieties and all the traits (Table 1). However, less difference could be detected between the effect of heat and drought stress for this parameter. The Plainsman $\mathrm{V}$ variety has smaller biomass than the other varieties tested, and this decreased to the greatest extent (to $58.86 \%$ of the control) in the $\mathrm{H}+\mathrm{D}$ treatment and to the smallest extent in response to heat stress (to $79.4 \%$ of the 

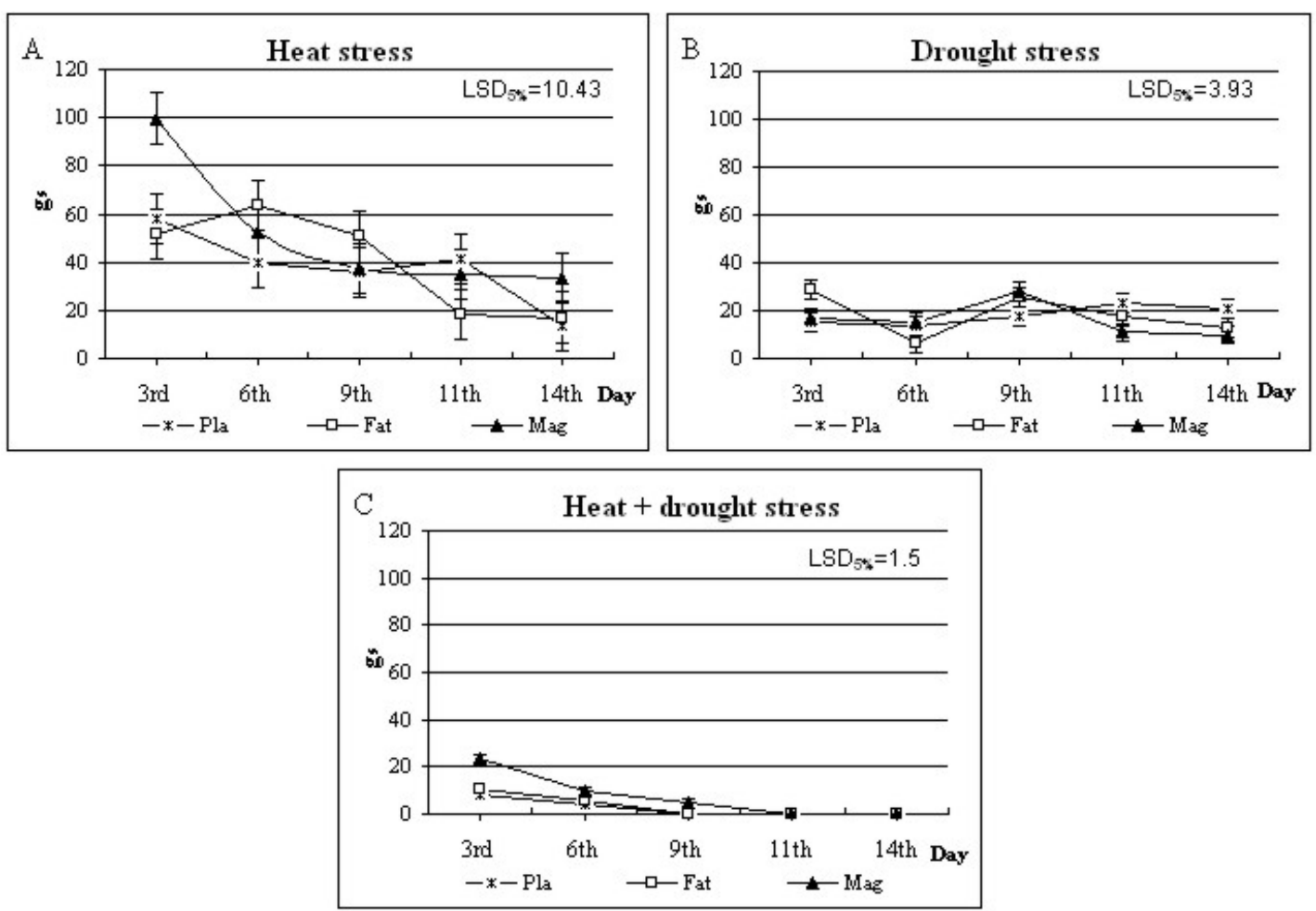

Figure 5. Changes in the stomatal conductance $\left(g_{s}\right)$ of winter wheats as a \% of the control during 15 days of treatment with heat stress (A), drought stress (B) and combined heat + drought stress (C) Pla - Plainsman V, Fat - Fatima 2, Mag - Mv Magma LSD ${ }_{5 \%}$ : Bar - represents the minimal difference statistically significant at the $P \leq 0.05$ level
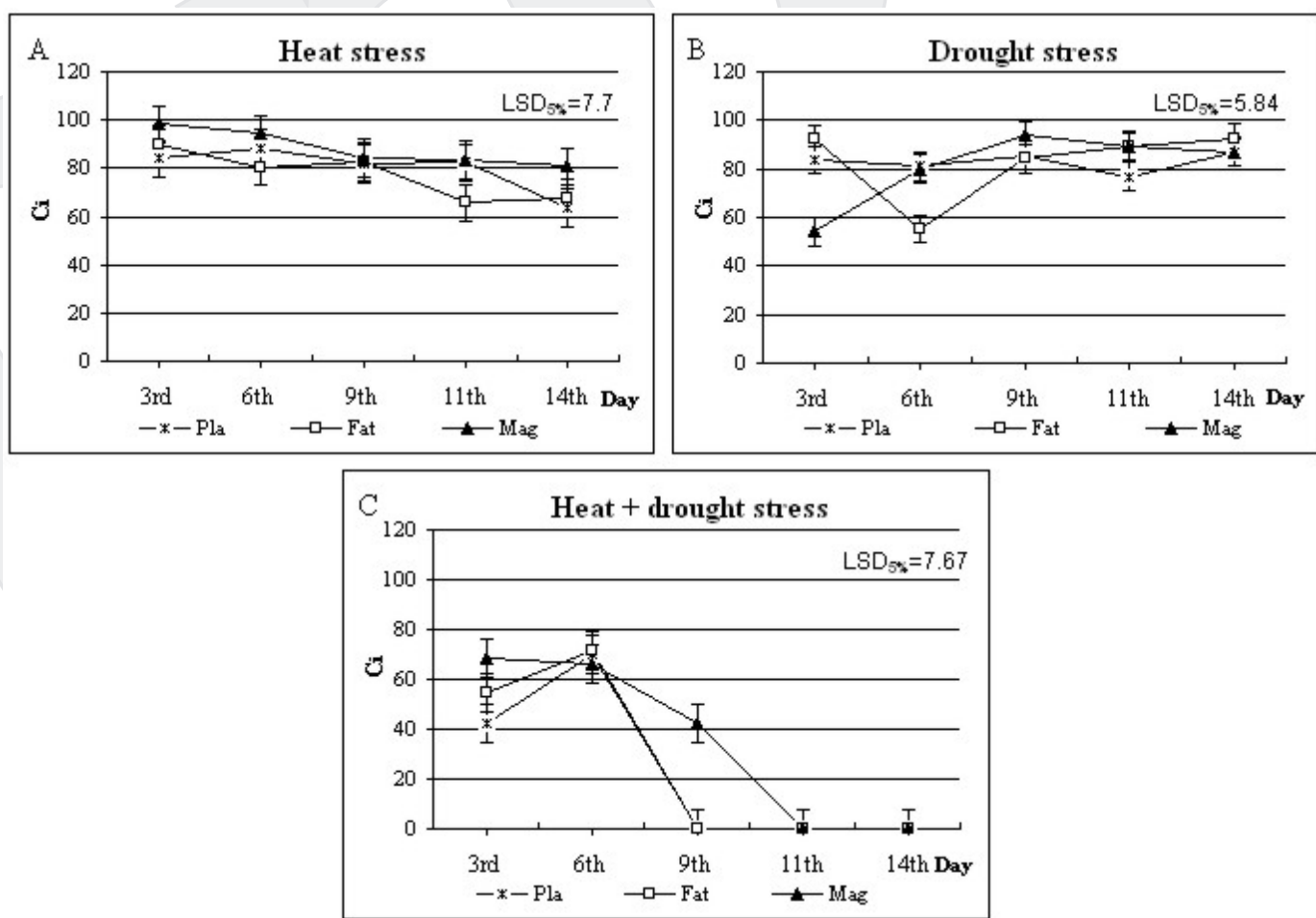

Figure 6. Changes in the $C_{i}$ values of winter wheats as a \% of the control during 15 days of treatment with heat stress (A), drought stress (B) and combined heat + drought stress (C) Pla - Plainsman V, Fat - Fatima 2, Mag - Mv Magma LSD ${ }_{5 \%}$ : Bar - represents the minimal difference statistically significant at the $\mathrm{P} \leq 0.05$ level 
control). Significant reductions were observed for both Fatima 2 and Mv Magma during both heat and drought stress, but the difference between the treatments was not significant. Among the varieties, the biomass of Fatima 2 exhibited the smallest decrease in response to heat stress (to $84.16 \%$ of the control), while the most sensitive response to drought stress in terms of biomass was given by Plainsman $\mathrm{V}$ (to $65.4 \%$ of the control).

The analysis of changes in the harvest index gave the best results for Mv Magma, as there was no significant reduction in this parameter during either heat or drought stress (Table 1). The changes observed in $\mathrm{HI}$ for Plainsman $\mathrm{V}$ and Fatima 2 were similar, though Plainsman $V$ appeared to have slightly better tolerance of drought. As in the case of biomass, the greatest reduction in $\mathrm{HI}$ was induced by the combined stress, which was the most pronounced for Plainsman $\mathrm{V}$ (to $43.8 \%$ of the control) and the least so for Mv Magma (to $69.3 \%$ of the control).

The stress treatments had the smallest influence on the grain number of the plants. The greatest reductions were observed for Plainsman $\mathrm{V}$, where significantly lower grain numbers were recorded in all three treatments (H: $75.84 \%, \mathrm{D}: 67 \%, \mathrm{H}+\mathrm{D}: 69.7 \%$ of the control values). The grain number of Fatima 2 was influenced to the least extent by the treatments, while a significant change was only recorded for Mv Magma after the combined stress $(79.3 \%)$.

The least reduction in the thousand-kernel weight was found for Plainsman $\mathrm{V}$ in the case of both heat stress (to $82.6 \%$ of the control) and drought stress (to $86.5 \%$ of the control) (Table 1 ). This was followed

\begin{tabular}{|c|c|c|c|c|c|c|}
\hline Treatment & Plainsman V & Fatima 2 & Mv Magma & $\mathrm{LSD}_{5 \%}$ & $\mathrm{LSD}_{1 \%}$ & $\mathrm{LSD}_{0.1 \%}$ \\
\hline \multicolumn{7}{|l|}{ Biomass } \\
\hline $\mathrm{C}$ & 5.30 & 6.00 & 6.48 & 0.61 & 0.81 & 1.03 \\
\hline $\mathrm{H}$ & $4.21^{\star \star \star}$ & $5.05^{\star *}$ & $5.12^{\star \star \star}$ & & & \\
\hline D & $3.47^{\star \star *}$ & $5.11^{* *}$ & $5.21^{\star * *}$ & & & \\
\hline$H+D$ & $3.12^{\star \star \star}$ & $4.36^{\star \star \star}$ & $4.29^{\star \star \star}$ & & & \\
\hline \multicolumn{7}{|l|}{$\mathrm{HI}$} \\
\hline C & 43.74 & 46.63 & 41.00 & 3.46 & 4.55 & 5.84 \\
\hline $\mathrm{H}$ & $34.33^{\star \star \star}$ & $32.91^{\star \star \star}$ & 41.56 & & & \\
\hline $\mathrm{D}$ & $37.90^{\star \star \star}$ & $34.26^{\star \star \star}$ & 39.68 & & & \\
\hline$H+D$ & $19.16^{\star \star \star}$ & $24.94^{\star \star \star}$ & $28.41^{\star \star \star *}$ & & & \\
\hline \multicolumn{7}{|c|}{ Grain number } \\
\hline C & 102.46 & 94.63 & 92.17 & 14.43 & 19.02 & 24.40 \\
\hline $\mathrm{H}$ & $77.71^{\star \star \star}$ & 94.42 & 91.69 & & & \\
\hline D & $68.71^{\star \star \star}$ & 92.13 & 84.17 & & & \\
\hline$H+D$ & $71.42^{\star \star \star}$ & 98.96 & $73.17^{\star}$ & & & \\
\hline \multicolumn{7}{|l|}{ TKW } \\
\hline C & 23.26 & 30.06 & 28.90 & 2.17 & 2.86 & 3.67 \\
\hline $\mathrm{H}$ & $19.22^{\star \star \star}$ & $18.20^{\star \star \star}$ & $22.91 * \star \star$ & & & \\
\hline D & $20.14^{* *}$ & $19.63^{\star \star \star}$ & 24.39 ** & & & \\
\hline$H+D$ & $8.7^{\star \star \star}$ & $11.29^{\star \star \star}$ & $17.68^{* \star *}$ & & & \\
\hline \multicolumn{7}{|l|}{ Grain yield } \\
\hline $\mathrm{C}$ & 2.34 & 2.79 & 2.64 & 0.27 & 0.36 & 0.46 \\
\hline $\mathrm{H}$ & $1.44^{\star \star *}$ & $1.66^{\star \star \star}$ & $2.13^{\star * *}$ & & & \\
\hline$D$ & $1.34^{\star \star \star}$ & $1.74^{\star \star \star}$ & $2.03^{\star \star \star}$ & & & \\
\hline$H+D$ & $0.61^{* \star *}$ & $1.10^{\star * \star}$ & $1.21^{\star \star \star}$ & & & \\
\hline
\end{tabular}

Table 1. Changes in the yield parameters of winter wheats in response to heat stress, drought stress and combined heat + drought stress.

C-control, $\mathrm{H}$ - heat stress, $D$-drought stress, $\mathrm{H}+\mathrm{D}$ - heat + drought stress; HI - Harvest index; TKW - Thousand-kernel weight Least significant differences (LSD) denoted by *, ** and *** proved significant at the $P \leq 0.05, P \leq 0.01$ and $P \leq 0.001$ levels, respectively 
by Mv Magma, while Fatima 2 proved to be the most sensitive. In the case of combined stress, however, Plainsman $\mathrm{V}$ exhibited the greatest reduction.

Plainsman $\mathrm{V}$ had the second lowest $(61.5 \%)$ grain yield (Fatima 2: $59.4 \%$, Mv Magma: $80.7 \%$ in response to $35^{\circ} \mathrm{C}$ ), as it exhibited the smallest reduction in thousand-kernel weight but the greatest drop in grain number (Table 1). By contrast Mv Magma exhibited smaller reductions in both grain number and thousandkernel weight, resulting in the highest yield in response to both heat stress $(80.7 \%)$ and drought $(76.9 \%)$ and to the combined stress (45.8\%). The yield of Fatima 2 also dropped significantly after drought treatment $(62.3 \%)$, but not to such a great extent as that of Plainsman V (to $57.2 \%$ of the control). This can be attributed to the fact that the grain number of Fatima 2 did not decrease to a significant extent 12 days after heading, unlike that of Plainsman V.

\section{Discussion}

In the present work three winter wheat cultivars exposed to heat, drought and combined heat + drought stress were monitored during the grain-filling period by comparing the physiological parameters commonly used for screening stress resistance, namely the photosynthetic performance of the flag-leaf and the grain yield.

A drop in the chlorophyll content may occur naturally in the course of aging, as the result of ripening. In this study no significant differences were observed in the chlorophyll contents of the control wheat plants during the 15-day stress treatments, which remained at a constant level. This suggests that the losses in chlorophyll were induced by the stress factors. This is in agreement with the findings of Ristic et al. [7]. According to Harding et al. [25] high temperature caused accelerated aging, leading to the activation of proteolytic enzymes, protein degradation and chlorophyll losses. Chlorophyll loss may be the consequence of the damage caused by heat stress in the thylakoid membranes and in PSII [7].

The physiological changes caused by drought and heat stress in the present experiments resulted in the rapid degradation of the leaf chlorophyll content, so the plants turned yellow earlier than the control plants. Significant reductions in the chlorophyll content were observed starting from the $11^{\text {th }}$ day of treatment after heat stress or drought alone, but only after the $3^{\text {rd }}$ day for the combined stress. This confirms the findings of other authors, who reported that the relative water content and chlorophyll content of the leaves decreased more rapidly in plants exposed to heat stress or were water deficit compared to the untreated plants $[15,26,27]$. Due to heat and drought stress there was a drastic reduction in photosynthetic activity, and harvest maturity was reached more quickly. Stress effects during the ripening of wheat may have accelerated aging processes, shortening the period during which assimilates formed in the course of photosynthesis were translocated to the grain, thus resulting in the grain ripening much earlier than under optimal conditions.

One reason for the decline in photosynthetic activity is stomatal closure; another is the negative regulation of photosynthesis in response to drought and/or high temperature. The present results confirmed those reported by Martinez et al. [28], who observed that drought after flowering led to a substantial acceleration of the chlorophyll degradation in wheat flag-leaves, followed by the degradation of Rubisco and the lightharvesting complex of PSII (LHCII).

In the present experiments the most rapid reduction in the effective quantum yield of PSII $\left(\Phi_{\text {PSII }}\right)$ was observed in the case of combined stress, while high temperature or drought alone only caused a more pronounced decrease after about the $9^{\text {th }}$ day of treatment. Major differences between the effects of heat and drought stress were not detected for the varieties tested.

Ristic et al. [7] found a close negative correlation between the decrease in chlorophyll content and the chlorophyll fluorescence parameter (ratio of constant fluorescence to the peak of variable fluorescence) that measures damage to the thylakoid membranes, suggesting that heat tolerance can be tested simply by measuring the chlorophyll content. In contrast, in the present work only a weak correlation (at the $10 \%$ level of probability) could be detected between $\Phi_{\text {PSII }}$ and the drop in the chlorophyll content (data not given). This could be explained by the much lower number of genotypes and by the fact that a different chlorophyll fluorescence parameter was used in the correlation analysis.

The usefulness of chlorophyll fluorescence for the screening of drought tolerance in wheat genotypes has been suggested by many experiments. However, the results are even more reliable if this is combined with other methods [29,30]. Although [30] found $\Phi_{\text {PSII }}$ to be a good indicator of changes in the quantum yield of leaf $\mathrm{CO}_{2}$ assimilation under certain conditions, it was not suitable for the estimation of absolute rates of $\mathrm{CO}_{2}$ assimilation, as this parameter $\left(\Phi_{\mathrm{PSII}}\right)$ is influenced by many metabolic and physiological factors that determine the rate of consumption of ATP and NADPH.

In addition to studying changes in chlorophyll fluorescence induction, it was important to investigate the photosynthetic efficiency of winter wheats under various stress conditions. The photosynthetic activity 
of plants is extremely complex, so in addition to net assimilation it is also important to evaluate changes in transpiration, stomatal conductance and intercellular $\mathrm{CO}_{2}$ concentration. The measurement of these photosynthetic parameters revealed differences not only between the stress treatments but also between the varieties.

The net assimilation of the varieties exhibited the smallest decrease in response to heat stress and the greatest after combined stress, while drought stress had an intermediate effect. The plants responded to a temperature of $35^{\circ} \mathrm{C}$ with enhanced transpiration, while they attempted to survive drought stress by reducing transpiration. The closing of the stomata served to avoid increased water loss. The reduction in stomatal conductance was similar to that in the transpiration. In the winter wheat varieties tested, heat stress caused a smaller decrease in stomatal conductance and drought a greater decline, while the most intense reduction in this trait was recorded for combined heat + drought stress, as also observed for the intercellular $\mathrm{CO}_{2}$ concentration.

The results obtained by Hassan [31] in wheat and Jiang and Huang [32] in Kentucky bluegrass showed the reducing effect of heat stress, drought and the interaction between these factors on the $P_{N}, g_{s}, C_{i}$ and chlorophyll fluorescence parameters, as also shown in the present work. However, these authors reported that heat stress caused a greater decline in $\mathrm{P}_{\mathrm{N}}$ than drought stress. This could be partly due to the fact that [31] applied a temperature of $40-42^{\circ} \mathrm{C}$, but the temperature used by Jiang and Huang [32] was $35^{\circ} \mathrm{C}$, as in the present work, so this could not explain the deviation in the results.

A joint evaluation of the photosynthetic parameters of the three winter wheat varieties indicated that $\mathrm{Mv}$ Magma had the best heat stress tolerance. It also had the best response to the combined stress treatment. Compared to the other varieties, both the chlorophyll content and the $\Phi_{\mathrm{PSII}}$ value decreased to a lesser extent in Mv Magma, as a percentage of the control. The net assimilation remained at the highest level throughout the treatment, with high values of transpiration and stomatal conductance. Plainsman $\mathrm{V}$ had the best drought tolerance, though in many cases the difference was not significant. This variety exhibited the smallest reduction in both the chlorophyll content and the $P_{N}$ value on the $11^{\text {th }}$ day of drought treatment, while it gave the weakest response to the $H+D$ treatment in terms of all the parameters tested. The variety Fatima 2 had the least tolerance of the stress treatments, exhibiting the greatest reduction in all the photosynthetic parameters. In the case of drought stress, however, it proved to have better net assimilation than $\mathrm{Mv}$ Magma, though the difference was only significant at the $10 \%$ level.
Genotypes that are able to maintain photosynthesis in the flag-leaf for a longer period are generally thought to yield more [33]. These authors stated that changes in the effective quantum yield of PSII depended on the genotypes and not on the sensitivity of the cultivars. Nor could a close correlation be detected between net $\mathrm{CO}_{2}$ assimilation $\left(\mathrm{P}_{\mathrm{N}}\right)$ and the drought sensitivity of the varieties in the case of water deficit: photosynthetic activity was found to cease earliest in drought-tolerant genotypes, while the senescence of the flag-leaves was observed 7 days later in the drought-sensitive cultivar. Similarly, In the present work, no correlation was found between the sensitivity of the varieties and the day on which the values of the parameters (such as net $\mathrm{CO}_{2}$ assimilation, effective quantum yield of PSII) declined.

Regarding the yield parameters, although [33] observed no reduction in the number of grains per spike in response to drought stress in Plainsman V, in the present work it was this variety that exhibited the greatest drop in the grain number (to $67 \%$ of the control). It should be noted that the plants of each variety were exposed to drought 12 days after the mean heading date of the variety, i.e. in exactly the same phenophase, so differences in the heading date could not explain the differences in grain number and the major reduction recorded for Plainsman V. In this experiment changes in yield parameters did not mirror the stress tolerance levels determined for the varieties at the physiological level, except in the case of Mv Magma, which exhibited the best heat tolerance in terms of yield. This variety also had the best tolerance of drought and combined stress, as confirmed by the high values of harvest index. The fact that Plainsman $V$ had the highest thousand-kernel weight suggested that it had better drought tolerance, but the substantial reduction in grain number led to lower yields than expected. As observed for the changes in physiological parameters, the yield of Fatima 2 dropped considerably compared to the control, suggesting that this variety had greater sensitivity to abiotic stress.

When Reynolds et al. [34] carried out correlation analysis between physiological and yield parameters they reported that $P_{N}$ and $g_{s}$ exhibited a significant correlation with the yield and biomass of the varieties in the booting, flowering and grain-filling stages. These authors also found a significant correlation between $P_{N}$ and the reduction in the chlorophyll content in the grainfilling stage. In the present work a close correlation between net photosynthetic assimilation and the yield was only detected from the $9^{\text {th }}$ day of drought stress onwards, while only weaker correlations were observed in all the other cases, which could have been partly due to the small number of varieties examined (data not shown). 
High temperature and drought stress after flowering was reported to have a much more pronounced effect on the parameters (grain yield, grain number, TKW, ripening date, etc.) than each stress factor had separately [35], as also found in the present work. However, while [35] reported that drought stress caused a greater reduction than heat stress, in the present work only a slight difference could be observed between the two treatments. Hassan [31], on the other hand, observed a $21 \%$ decrease in grain yield due to drought and a $26 \%$ increase after heat stress.

The measurement of chlorophyll content and the determination of various parameters related to chlorophyll fluorescence induction could be suitable for the estimation of plant stress tolerance. Nevertheless, to make testing more precise, it is advisable to complement this method with measurements of net assimilation or stomatal conductance. Among the quantitative trait characteristics of stress tolerance, the grain yield should

\section{References}

[1] Farooq M., Bramley H., Palta J.A., Siddique K.H.M., Heat stress in wheat during reproductive and grain-filling phases, Crit. Rev. Plant Sci., 2011, 30, 491-507

[2] Al-Khatib K., Paulsen G.M., Mode of high temperature injury to wheat during grain development, Plant Physiol., 1984, 61, 363-368

[3] Scott A.H., James A.G., Gary M.P., Photosynthetic decline from high temperature stress during maturation of wheat. Interaction with senescence processes, Plant Physiol., 1990, 92, 648-653

[4] Schreiber U., Berry J.A., Heat-induced changes of chlorophyll fluorescence in intact leaves correlated with damage of photosynthetic apparatus, Planta, 1977, 136, 233-238

[5] Xu Q., Paulsen A.Q., Guikema J.A., Paulsen G.M., Functional and ultrastructural injury to photosynthesis in wheat by high temperature during maturation, Environ. Exp. Bot., 1995, 35, 43-54

[6] Bernacchi C.J., Portis A.R., Nakano H., von Caemmerer S., Long S.P., Temperature response of mesophyll conductance. Implications for the determination of Rubisco enzyme kinetics and for limitations to photosynthesis in vivo, Plant Physiol., 2002, 130, 1992-1998

[7] Ristic Z., Bukovnik U., Prasad P.V.V., Correlation between heat stability of thylakoid membranes and loss of chlorophyll in winter wheat under heat stress, Crop Sci., 2007, 47, 2067-2073 definitely be regarded as one of the most important parameters. A major aim of plant breeding is to achieve high yield potential, so the determination of grain weight is essential. This parameter, which gives the best reflection of the stress tolerance of wheat plants, is a function of the grain number and the thousand-kernel weight. As yield traits are not always closely correlated with physiological parameters, the joint consideration of these properties is essential if the stress tolerance of individual genotypes is to be precisely determined.

\section{Acknowledgements}

This research was funded by the projects TÁMOP4.2.2.b-10/1-2010-0025, TÁMOP-4.2.2.A11/1KONV-2012-0064 and DROPS (EU-FP7 No. 244374) and by a grant from the National Scientific Research Fund (OTKA K-105949).

[8] Reynolds M.P., Balota M., Delgado M.I.B., Amani I., Fischer R.A., Physiological and morphological traits associated with spring wheat yield under hot, irrigated conditions, Aust. J. Plant Physiol., 1994, 21, 717-730

[9] Fokar M., Nguyen H.T., Blum A., Heat tolerance in spring wheat: I. Estimating cellular thermotolerance and its heritability, Euphytica, 1998, 104, 1-8

[10] Xu X.L., Zhang Y.H., Wang Z.M., Effect of heat stress during grain filling on phosphoenolpyruvate carboxylase and ribulose-1,5-bisphosphate carboxylase/ oxygenase activities of various green organs in winter wheat, Photosynthetica, 2004, 42, 317-320

[11] Salvucci M.E., Crafts-Brandner S.J., Inhibition of photosynthesis by heat stress: the activation state of Rubisco as a limiting factor in photosynthesis, Physiol. Plant., 2004, 120, 179-186

[12] Chaves M.M., Pereira J.S., Maroco J., How plants cope with water stress in the field. Photosynthesis and growth, Ann. Bot., 2002, 89, 907-916

[13] Wise R.R., Ortiz-Lopez A., Ort D.R., Spatial distribution of photosynthesis during drought in field-grown and acclimated and non-acclimated growth chamber-grown cotton, Plant Physiol., 1991, 100, 26-32

[14] Shanggunan Z., Shao M., Dyckmans J., Interaction of osmotic adjustment and photosynthesis in winter wheat under soil drought, J. Plant Physiol., 1999, 154, 753-758 
[15] Yang J., Zhang J., Wang Z., Zhu Q., Wang W., Remobilization of carbon reserves in response to water deficit during grain filling of rice, Field Crops Res., 2001b, 71, 47-55

[16] Yang J., Zhang J., Wang Z., Zhu Q., Liu L., Water deficit-induced senescence and its relationship to the remobilization of pre-stored carbon in wheat during grain filling, Agron J., 2001a, 93, 196-206

[17] Gregersen P.L., Holm P.B., Transcriptome analysis of senescence in the flag leaf of wheat, Plant Biotechnol. J., 2007, 5, 192-206

[18] Moffat J.M., Sears G., Cox T.S., Paulsen G.M., Wheat high temperature tolerance during reproductive growth. I. Evaluation by chlorophyll fluorescence, Crop Sci., 1990, 30, 881-885

[19] Mohammadi M., Karimizadeh R.A., Naghavi M.R., Selection of bread wheat genotypes against heat and drought tolerance based on chlorophyll content and stem reserves, J. Agric. Soc. Sci., 2009, 5, 119-122

[20] Tischner T., Rajkainé Végh K., Kőszegi B., Effect of growth medium on the growth of cereals in the phytotron, Acta Agron. Hung., 1997, 45, 187-193

[21] Tottman D.R., Makepeace, R.J., An explanation of the decimal code for the growth stages of cereals, with illustrations, Ann. Appl. Biol., 1979, 93, 221234

[22] Genty B., Briantais J.M., Baker N.R., The relationship between the quantum yield of photosynthetic electron transport and quenching of chlorophyll fluorescence, Biochem. Biophys. Acta, 1989, 990, 87-92

[23] Donald C.M., In search of yield, J. Aust. I. Agr. Sci., 1962, 28, 171-178

[24] Láng L., Kuti C., Bedő Z., Computerized data management system for cereal breeding, Euphytica, 2001, 119, 235-240

[25] Harding S.A., Guikema J.A., Paulsen G.M., Photosynthetic decline from high temperature stress during maturation of wheat: I. Interaction with senescence processes, Plant Physiol., 1990, $92,648-653$
[26] Jiang Y., Huang B., Drought and heat stress injury to two cool-season turfgrasses in relation to antioxidant metabolism and lipid peroxidation, Crop Sci., 2001, 41, 436-442

[27] Bencze S., Veisz O., Bedő Z., Effects of elevated $\mathrm{CO} 2$ and high temperature on the photosynthesis and yield of wheat, Cereal Res. Commun., 2005, 33, 385-388

[28] Martinez D.E., Luquez V.M., Bartoli C.G., Guiamét J.J., Persistence of photosynthetic components and photochemical efficiency in ears of waterstressed wheat (Triticum aestivum L), Physiol. Plant., 2003, 119, 1-7

[29] Flagella Z., Pastore D., Campanile R.G., Di Fonzo $\mathrm{N}$., The quantum yield of photosynthetic electron transport evaluated by chlorophyll fluorescence as an indicator of drought tolerance in durum wheat, J. Agric. Sci., 1995, 125, 325-329

[30] Baker N.R., Chlorophyll fluorescence: A probe of photosynthesis in vivo, Annu. Rev. Plant Biol., 2008, 59, 89-113

[31] Hassan I.A., Effects of water stress and high temperature on gas exchange and chlorophyll fluorescence in Triticum aestivum L., Photosynthetica, 2006, 44, 312-315

[32] Jiang Y., Huang B., Effects of drought or heat stress alone and in combination on Kentucky bluegrass, Crop Sci., 2000, 40, 1358-1362

[33] Guóth A., Tari I., Gallé Á., Csiszár J., Pécsváradi A., Cseuz L., Erdei L., Comparison of the drought stress responses of tolerant and sensitive wheat cultivars during grain filling: Changes in flag leaf photosynthetic activity, ABA levels, and grain yield, J. Plant Growth Regul., 2009, 28, 167-176

[34] Reynolds M.P., Delgado B.M.I., Gutiérrez-Rodríguez M., Larqué-Saavedra A., Photosynthesis of wheat in a warm, irrigated environment I: Genetic diversity and crop productivity, Field Crops Res., 2000, 66, 37-50

[35] Kaur V., Behl R.K., Grain yield in wheat as affected by short periods of high temperature, drought and their interaction during pre- and post-anthesis stages, Cer. Res. Commun., 2010, 38, 514-520 